\title{
Tumorigenic Potential of Mononucleated Small Cells of Hodgkin Lymphoma Cell Lines
}

Jun-ichiro Ikeda, Suhana Mamat, Tian Tian, Yi Wang, Nur Rahadiani, Katsuyuki Aozasa, and Eiichi Morii

From the Department of Pathology, Osaka University Graduate School of Medicine, Osaka, Japan

Tumor cells with tumorigenic potential are limited to a small cell population known as cancer stem cells (CSCs). CSCs yield both CSCs and non-CSCs, whereas non-CSCs do not yield CSCs. CSCs have not been identified in any malignant lymphomas. Hodgkin lymphoma (HL) is a mostly B-cell neoplasm that can be diagnosed by the presence of multinucleated (ReedSternberg; RS) cells admixed with Hodgkin cells with distinct nucleoli and various inflammatory cells. Here, the tumorigenic potential of cells with a single nucleus (S) and cells with multiple nuclei (M), which may be equivalent to Hodgkin and RS cells, respectively, was examined in HL cell lines L1236 and L428. Cultures of single $S$ cells yielded both $S$ and $M$ cells, whereas $M$ cell cultures yielded only $M$ cells. When either cultured in methylcellulose or inoculated into NOD/SCID mice, the colony number and tumor size were both larger in $S$ than in $M$ cells. Concentrations of intracellular reactive oxygen species (ROS) were at low levels in a portion of $S$ cells that abundantly expressed FoxO3a, a transcription factor that regulates ROS-degrading enzymes. In clinical samples of HL, FoxO3a was expressed in mononuclear Hodgkin cells but not in multinucleated RS cells. These findings suggest that smaller cells or Hodgkin cells that show low-ROS concentrations and high FoxO3a expression levels might be candidates for HL CSCs. (Am J Pathol 2010, 177:3081-3088; DOI: 10.2353/ajpath.2010.100089)

Tumors consist of heterogenous cell populations derived from a single clone. Recently, it has been demonstrated that tumor cells with tumorigenic potential are limited to a small population, called cancer-initiating cells or cancer stem cells (CSCs), in several tumors, such as leukemia, breast, brain, and colon cancers. ${ }^{1-8}$ CSCs yield both CSCs and non-CSCs, whereas non-CSCs do not yield CSCs. ${ }^{8}$ CSCs efficiently efflux antitumor chemicals and degrade reactive oxygen species (ROS) that are related to radiation-induced apoptosis. ${ }^{9}$ These characteristics enable CSCs to be resistant to antitumor drugs and radiation therapy. To date, CSCs have not been identified in any kinds of malignant lymphomas.

Cell origin of Hodgkin lymphoma (HL) had been controversial, but the studies based on molecular biology revealed that $\mathrm{HL}$ is mostly a neoplasia of $\mathrm{B}$ lymphocyte. $^{10,11} \mathrm{HL}$ can be diagnosed by the presence of multinucleated Reed-Sternberg (RS) cells and mononuclear Hodgkin cells intermingled with small lymphocytes and various inflammatory cells. The RS cells are regarded as pathognomonic for HL. The RS and Hodgkin cells share cell markers, such as CD15 and CD30, but the proliferation potential in the RS cells was reported to be lower than that of Hodgkin cells. ${ }^{12}$ To date, any markers that differentiate Hodgkin cells from RS cells have not been established. Here, a population showing CSC character was examined in $\mathrm{HL}$ cell lines $\mathrm{L} 1236$ and $\mathrm{L} 428 .{ }^{13,14}$ Tumorigenic potential and ROS-expelling ability were observed mainly in a portion of small-sized mononuclear Hodgkin cells. Large-sized RS-like cells appeared to be derived from a portion of small-sized Hodgkin cells. Hodgkin cells possess properties suggestive of CSCs in $\mathrm{HL}$.

\section{Materials and Methods}

\section{Cell Line}

Hodgkin lymphoma cell lines L1236 and L428 were purchased from Deutsche Sammlung von Mikroorganismen and Zellkulturen (Braunschweig, Germany). Cells were cultured in RPMl 1640 (Sigma, St Louis, MO) supplemented with 10\% fetal calf serum (Nippon Bio-SupplyCenter, Tokyo, Japan).

\section{Two Populations of Cells}

A portion of cultured cells was cytospun on poly-L-lysinecoated glass slides at $1500 \mathrm{rpm}$ for 3 minutes and stained with

Supported by grants from the Ministry of Education, Culture, Sports, Science, and Technology and from the Osaka Cancer Research Foundation.

Accepted for publication July 29, 2010

Address reprint requests to Eiichi Morii, M.D., Department of Pathology, Graduate School of Medicine, Osaka University, Yamada-oka 2-2, Suita 565-0871, Japan. E-mail: morii@patho.med.osaka-u.ac.jp. 
Table 1. Cell Size of $S$ and $M$ Cells in Hodgkin Lymphoma Cell Lines

\begin{tabular}{lcc}
\hline & L1236 & L428 \\
\hline $\mathrm{S}$ & $29.6 \pm 7.8 \mu \mathrm{m}$ & $21.0 \pm 4.8 \mu \mathrm{m}$ \\
$\mathrm{M}$ & $49.5 \pm 19.5 \mu \mathrm{m}$ & $32.8 \pm 11.9 \mu \mathrm{m}$ \\
$P$ value between & $<0.001$ & $<0.001$ \\
$\quad \mathrm{~S}$ and M & & \\
\hline
\end{tabular}

Giemsa solution. Cells with a single and multinucleus (more than two nuclei) were named as $S$ and $M$ cells, respectively. The mean size and SD of S and M cells are shown in Table 1. As observed by Wolf et $\mathrm{al}^{13}$ there was a limited number of large-sized cells (Figure 1A), mostly with multinucleus.

\section{Limiting Dilution}

Cells were counted and diluted to the concentration at one cell per $100 \mu \mathrm{l}$ of the medium. Then, $100 \mu \mathrm{l}$ was

\section{A}

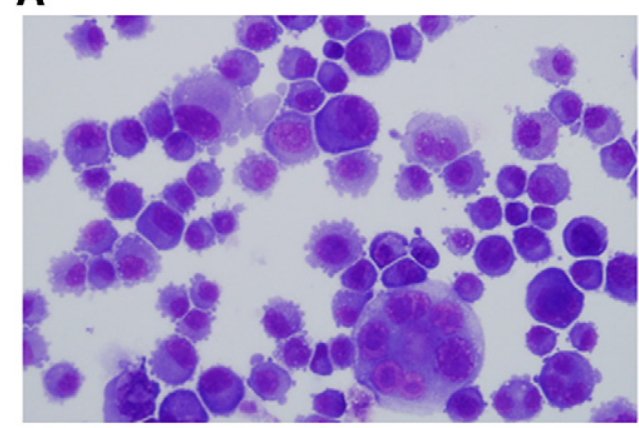

$\mathbf{L 1 2 3 6}$

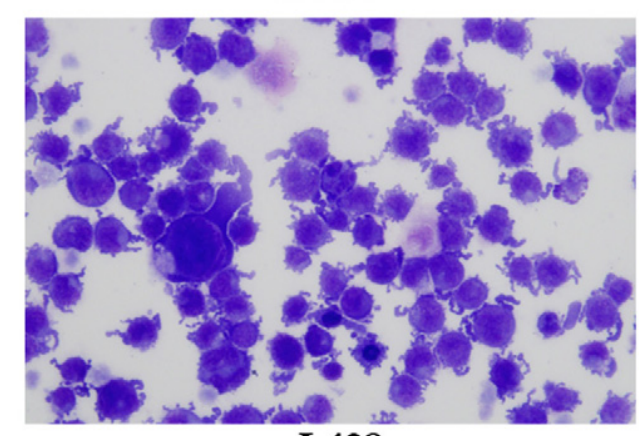

L428

\section{B}

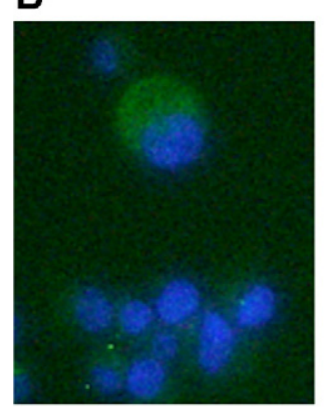

CD15

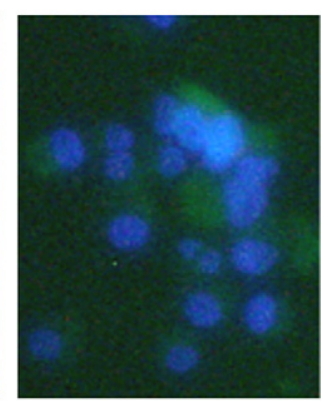

CD30
Figure 1. Typical morphology of HL cell lines L1236 and L428. A: Giemsa staining of original L1236 and L428 cells. B: Immunostaining for CD15 and CD30.
Table 2. Proportion of Multinucleated Cells in S, Mixed, and M Wells of the L1236 Cell Line

\begin{tabular}{cccc}
\hline $\begin{array}{c}\text { Type of } \\
\text { Well }\end{array}$ & $\begin{array}{c}\text { Proportion of } \\
\text { Multinucleated } \\
\text { Cells }(\%)\end{array}$ & $\begin{array}{c}P \text { Value } \\
\text { versus S }\end{array}$ & $\begin{array}{c}P \text { Value } \\
\text { versus } M\end{array}$ \\
\hline S & $10.2 \pm 1.5$ & NA & $<0.001$ \\
mixed & $19.0 \pm 0.1$ & $<0.01$ & $<0.001$ \\
$M$ & $80.6 \pm 2.7$ & $<0.001$ & NA \\
\hline
\end{tabular}

NA, not applicable.

cultured in each well of 96-well plates to determine the replication capacity of a single cell. After 2 weeks, each well was checked under a phase contrast microscopy to determine the number and size of cells. At Giemsa staining, three types of wells were found; a well exclusively containing $S$ cells, $M$ cells, and mixed $S$ and $M$ cells. Because cells did not proliferate in several wells, the sum of percentage of $\mathrm{S}$, mixed, and $\mathrm{M}$ wells was not 100. The proportion of multinucleated cells in $S$, mixed, and $M$ wells is shown in Table 2.

\section{Immunofluorescence for CD15 and CD30}

Cells were cytospun on poly-L-lysine-coated glass slides at $1500 \mathrm{rpm}$ for 3 minutes, fixed with 10\% formalin for 10 minutes, and treated with $0.25 \%$ Triton $\mathrm{X}-100$ solution for 10 minutes. After blocking with 5\% bovine serum albumin (Sigma), cells were incubated with anti-CD15 or antiCD30 antibody (DAKO A/S, Glostrup, Denmark). Then, cells were treated with Alexa Fluor 488 anti-mouse IgG (Invitrogen, Carlsbad, CA). As the negative control, staining was carried out in the absence of primary antibody.

\section{Immunocytochemistry for Cell Cycle Proteins (Ki-67 and Cyclin D2) and the Uptake of Bromodeoxyuridine (BrdU)}

Cells were cytospun, fixed with $10 \%$ formalin for 10 minutes, and treated with $0.25 \%$ Triton $\mathrm{X}-100$ solution for 10 minutes. After treatment with peroxidase blocking solution (DAKO), cells were incubated with anti-Ki-67 (DAKO) and anti-cyclin D2 (Abcam, Cambridge, UK) antibodies. Then, cells were treated with ChemMate EnVision kit (DAKO). DAB (DAKO) was used as a chromogen. As a negative control, staining was carried out in the absence of primary antibody.

The uptake of BrdU was examined using BrdU in situ detection kit (BD Biosciences, Franklin Lakes, NJ) according to the manufacturer's manual.

\section{In Vitro Colony Formation Assay}

The suspended 1000 cells were plated in culture dishes with $1 \mathrm{ml}$ of methylcellulose-containing DMEM supplemented with $15 \%$ FCS. The number of colonies was counted on day 14 . 


\section{Mice and Xenograft Transplantation}

Six- to 8-week-old female nonobese diabetic/severe combined immunodeficient (NOD/SCID) mice were purchased from Charles River Laboratories Japan and kept under specific pathogen-free conditions. Before xenotransplantation, the mice were deeply anesthetized. All animal experiments were done according to the guideline of Osaka University Animal Center and approved by the institutional review board of committee of animal experiments. In the previous study, ${ }^{13} 2 \times 10^{7}$ cells were injected for xenotransplantation. In this study, however, total number of $\mathrm{M}$ cells was prepared at $2 \times 10^{3}$, because of low proliferative potential of $\mathrm{M}$ cells. Then, $2 \times$ $10^{3}$ cells were used for xenotransplantation, and this was enough to form tumors by $S$ cells. $S$ and $M$ were suspended in $0.2 \mathrm{ml}$ of Matrigel (BD), and were injected subcutaneously into the frank of left and right side of the same animal, respectively. Tumor volume was estimated using the formula: (width) ${ }^{2} \times$ (length)/2 according to the report by Meyer-Siegler et al. ${ }^{15}$

\section{Assay for Intracellular ROS Level}

Cells were incubated with $10 \mu \mathrm{mol} / \mathrm{L}$ of 5-(and-6)-chloromethyl-2',7'-dichlorodihydrofluorescein diacetate, acetyl ester (CM- $\mathrm{H}_{2}$ DCFDA, Invitrogen) and $100 \mu \mathrm{mol} / \mathrm{L}$ of $\mathrm{H}_{2} \mathrm{O}_{2}$ at $37^{\circ} \mathrm{C}$ for 20 minutes. Dead cells were stained with propidium iodide. ROS-high cells were stained in green and dead cells in red. At least $200 \mathrm{~S}$ and M cells were examined, and the proportion of ROS-high viable cells was counted.

\section{Immunocytochemistry for FoxO3a and Catalase}

FoxO3a and catalase expression was immunocytochemically examined with anti-FoxO3a antibody (Cell Signaling Technology Inc, Beverly, MA) and anti-catalase antibody (Sigma, St. Louis, MO). Cells were cytospun on poly-Llysine-coated glass slides at 1500 rpm for 3 minutes, fixed with $10 \%$ formalin for 10 minutes and treated with $0.25 \%$ Triton X-100 solution for 10 minutes. After treatment with peroxidase blocking solution (DAKO), cells were incubated with anti-FoxO3a and anti-catalase antibodies diluted at $\times 250$ and $\times 200$, respectively. Then, cells were treated with ChemMate EnVision kit (DAKO). DAB (DAKO) was used as a chromogen. As the negative control, staining was carried out in the absence of primary antibody. At least $200 \mathrm{~S}$ and $\mathrm{M}$ cells were examined, and the proportion of FoxO3a expressing cells was counted.

\section{Flow Cytometry and Real-Time Quantitative} Reverse Transcription-Polymerase Chain Reaction (qRT-PCR)

Cells were stained with $\mathrm{CM}-\mathrm{H}_{2}$ DCFDA, and ROS-high and ROS-low cells were sorted with FACSAria (Becton Dickinson, Franklin Lakes, NJ). Total RNA was extracted from sorted cells using RNeasy RNA extraction kit (Qia- gen, Valencia, CA) according to the manufacturer's protocol, and cDNA was synthesized using oligo (dT) primers and SuperScript III reverse transcriptase (Invitrogen). The qRT-PCR was done with an ABI PRISM 7700 instrument (Applied Biosystems, Foster City, CA) using Taqman probe/primer sets specific for human FoxO3a. GAPDH was used as a reference for gene amplification (Applied Biosystems).

\section{Immunohistochemistry for FoxO3a}

FoxO3a expression was immunocytochemically examined in clinical samples from 13 cases with Hodgkin lymphoma with anti-FoxO3a antibody. Histological specimens were fixed in $10 \%$ formalin and routinely processed for paraffin-embedding. Sections were cut at 4 $\mu \mathrm{m}$ thickness. After antigen retrieval with Pascal pressurized heating chamber (DAKO), the sections were incubated with anti-FoxO3a antibody diluted at $\times 250$. Then, cells were treated with ChemMate EnVision kit (DAKO). DAB was used as a chromogen. As the negative control, staining was carried out in the absence of primary antibody. The study was approved by the ethical review board of Graduate School of Medicine, Osaka University. Two cases contained a limited number of RS cells. In these cases, approximately $20 \mathrm{RS}$ cells and the surrounding Hodgkin cells were examined. In the remaining cases, at least $50 \mathrm{RS}$ cells and the surrounding Hodgkin cells were examined.

\section{Effect of Insulin and PI3K Inhibitor}

To study the effect of insulin on the formation of M cells, insulin was added to culture medium of $S$ cells at a final concentration of $0,1,3,5,10$, and $50 \mu \mathrm{g} / \mathrm{ml}$. To study the role of phosphatidylinositol-3 kinase (PI3K), PI3K inhibitor LY294002 (Calbiochem, Darmstadt, Germany) was added to cultures medium of $\mathrm{S}$ cells at a final concentration of 0 , $1,5,10,20,50 \mu \mathrm{mol} / \mathrm{L}$ and incubated at $37^{\circ} \mathrm{C}$ for 40 minutes. After that, insulin was added at a final concentration of 0 and $10 \mu \mathrm{g} / \mathrm{ml}$. After 7 days, at least 1000 cells were cytospun, stained with Giemsa, and evaluated for the percentage of $\mathrm{M}$ cells. Expression level of FoxO3a was examined with immunocytochemistry.

\section{Statistical Analysis}

Statistical analyses were performed using Student's $t$ tests. The values are shown as the mean \pm SE of at least three experiments. The $P$ values of less than 0.05 were considered to be statistically significant.

\section{Results}

\section{Single Cell Culture of HL Cell Lines}

$\mathrm{HL}$ cell lines contained two population of cells, S and M cells (Figure 1A). The mean size and SD of $S$ and $M$ cells were shown in Table 1. Both S and M cells expressed CD15 and 


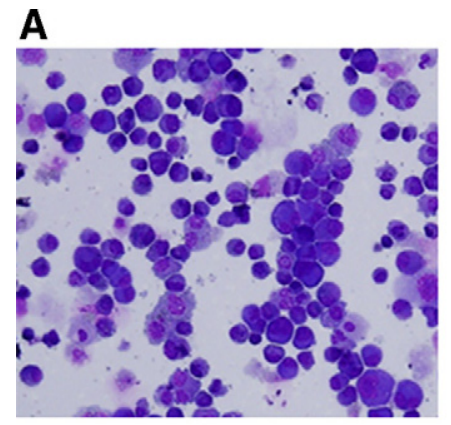

S

B

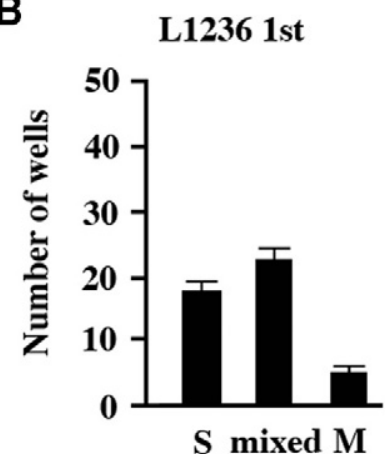

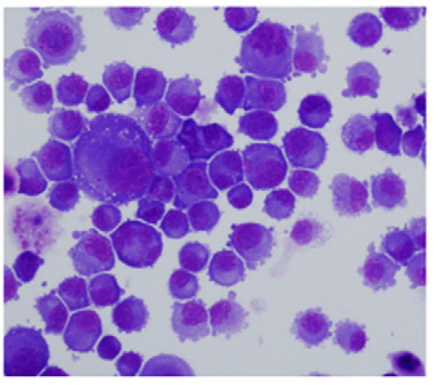

mixed

L1236 2nd

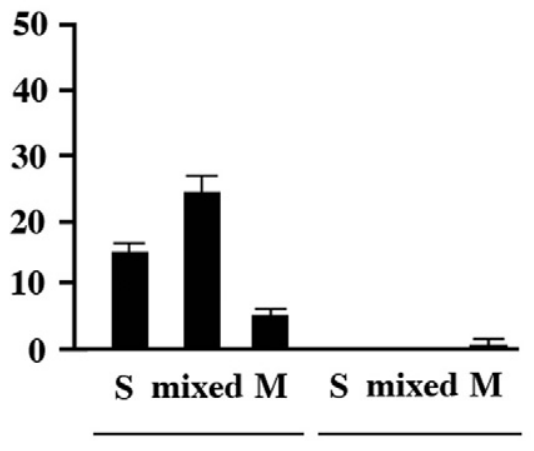

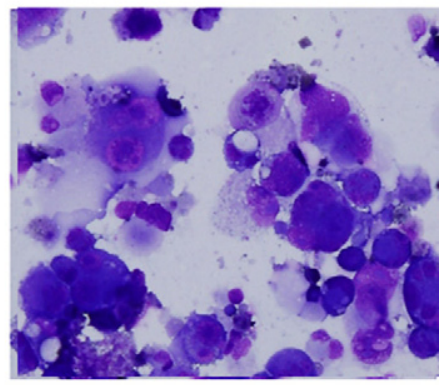

M

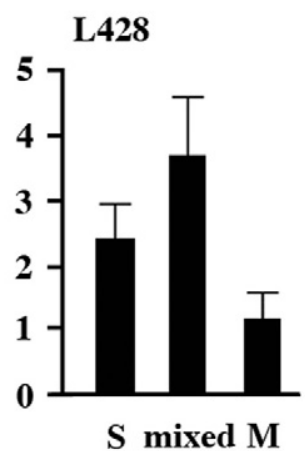

S

M

Figure 2. A limiting dilution of HL cell lines. A: When a single cell culture was done, wells containing exclusively S cells, mixed cell populations, or M cells were obtained. The representative fields of L1236 were shown. B: Number of wells containing S, mixed, and M cells per 100 wells is shown. A single cell culture from the original L1236 (left), from an S or M cell (middle), and a single cell culture from the original L428 culture (right). Because of the presence of wells without any cellular proliferation, the sum of the well number was not 100 .

CD30 (Figure 1B). To evaluate the relation between $\mathrm{S}$ and $\mathrm{M}$ cells, a single cell culture of L1236 was performed with limiting dilution. After 14 days, the size of proliferating cells in each well was checked with Giemsa staining and was categorized as wells containing $S$ cells, mixed $S$ and $M$ cells, or $M$ cells (Figure 2A). The number of wells with $S$, mixed, and $M$ cells per 100 wells was $18.1,24.7$, and 5.2 wells, respectively (mean of three independent experiments, Figure 2B). Next, a single cell culture was repeated with $S$ and $M$ cells. When a single cell culture of $S$ cells was done, number of wells with S, mixed, and M cells was 15.6, 26.0, and 3.1 wells per 100 wells. When a single cell culture of $M$ cells was done, number of wells with $S$, mixed, and $M$ cells was 0, 0, and 1.0 wells per 100 wells (Figure 2B). These findings indicated that $S$ cells yielded both $S$ and $M$ cells. The $\mathrm{M}$ cells possessed a limited proliferative potential and could not yield $S$ cells. A limiting dilution was carried out with another HL cell line L428. As observed in L1236, the number of wells with $\mathrm{M}$ cells was lower than that of $\mathrm{S}$ and mixed cells (Figure 2B).

\section{Proliferative Activity of S and M Cells}

Proportion of Ki-67-positive cells was higher in S than in $M$ cells of $L 1236$ and $L 428$ (Figure $3 A$ ). The proportion of
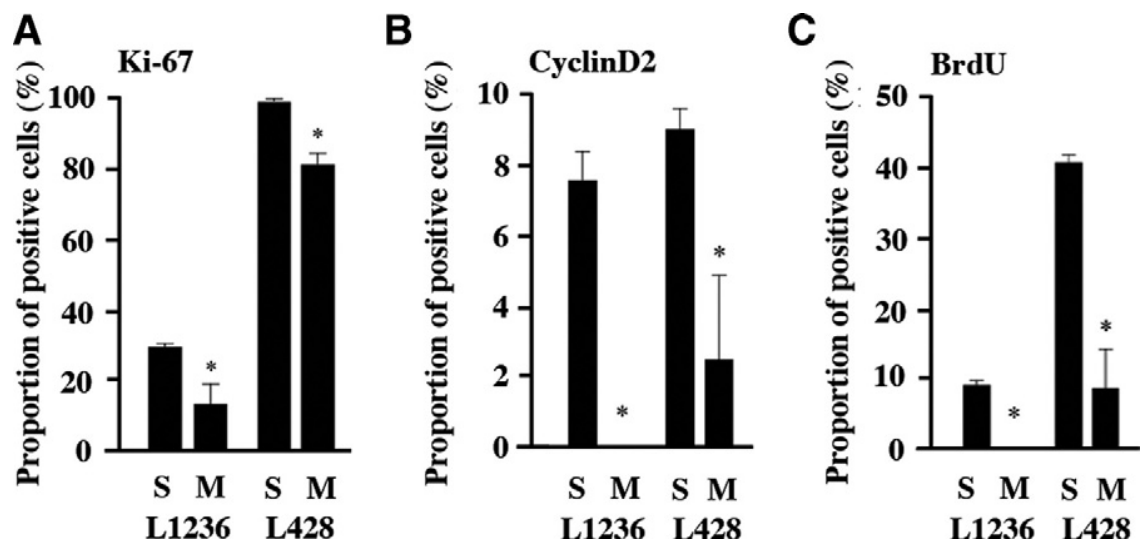

Figure 3. Analysis of proliferative potential The proportion of Ki-67- (A) and cyclin D2- (B) positive cells and BrdU-uptaking cells (C) was compared between $\mathrm{S}$ and $\mathrm{M}$ cells of L1236 and L428. The values are the mean $\pm \mathrm{SE}$ of three experiments. ${ }^{*} P<0.05$ by the Student's $t$-test. 


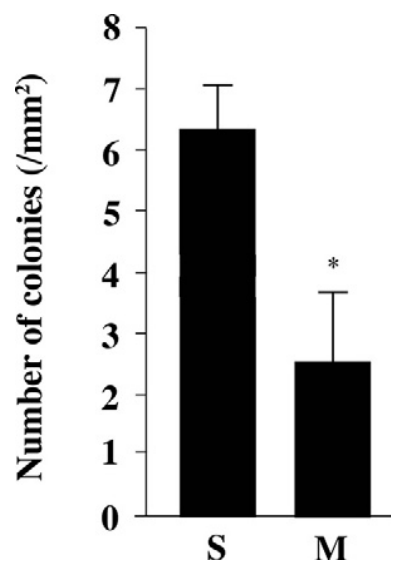

Figure 4. In vitro colony formation assay. The number of colonies by culture of $\mathrm{S}$ and $\mathrm{M}$ cells in methylcellulose are shown. The values are the mean $\pm \mathrm{SE}$ of three experiments. ${ }^{*} P<0.05$ by the Student's $t$-test.

cyclin D2-positive cells (Figure 3B) and that of BrdUuptaking cells (Figure $3 \mathrm{C}$ ) were also higher in S than in $\mathrm{M}$ cells.

\section{In Vitro Colony Formation Assay and NOD/SCID Mouse Injection}

To assess colony formation ability of $\mathrm{S}$ and $\mathrm{M}$ cells, both types of cells were plated in methylcellulose-containing DMEM supplemented with $15 \%$ FCS. Number of colonies obtained from $\mathrm{S}$ cells was significantly higher than that from $M$ cells (Figure 4).

To examine the tumorigenicity in vivo, $\mathrm{S}$ and $\mathrm{M}$ cells were injected into the left and right flank of NOD/SCID mice. At 2 weeks after the injection, tumor mass was found only in the injected site of $\mathrm{S}$ cells: the volume of tumor was $215.4 \pm 122.7 \mathrm{~mm}^{2}, 813.6 \pm 148.6 \mathrm{~mm}^{2}$, and $1510.6 \pm 430.3 \mathrm{~mm}^{2}$, at day 18,22 , and 26 , respectively (Figures 5, A-C). Tumor derived from $\mathrm{S}$ cells consisted of both $S$ and $M$ cells (Figure 5D). No tumor was found in the injected site of $\mathrm{M}$ cells throughout the observed period.

\section{ROS Concentration in S and M Cells}

CSCs are known to contain a lower level of ROS than non-CSCs. Therefore, the level of ROS was examined in L1236 cells after the addition of $\mathrm{H}_{2} \mathrm{O}_{2}$. Cells containing high ROS showed green fluorescence after the incubation with $\mathrm{CM}_{-} \mathrm{H}_{2}$ DCFDA. Although most $\mathrm{M}$ cells and a majority of $S$ cells were stained in green, approximately $10 \%$ of $\mathrm{S}$ cells showed a marginal green fluorescence, indicating that the level of ROS was low in these $S$ cells (Figure 6).

\section{Expression of FoxO3a}

It is known that $\mathrm{ROS}$ level and FoxO3a level are inversely correlated, because FoxO3a enhances the expression of ROS-degradation enzymes, such as superoxide dimustase and catalase. In fact, the expression level of FoxO3a was higher in ROS-low cells than in ROS-high cells (Fig-
A

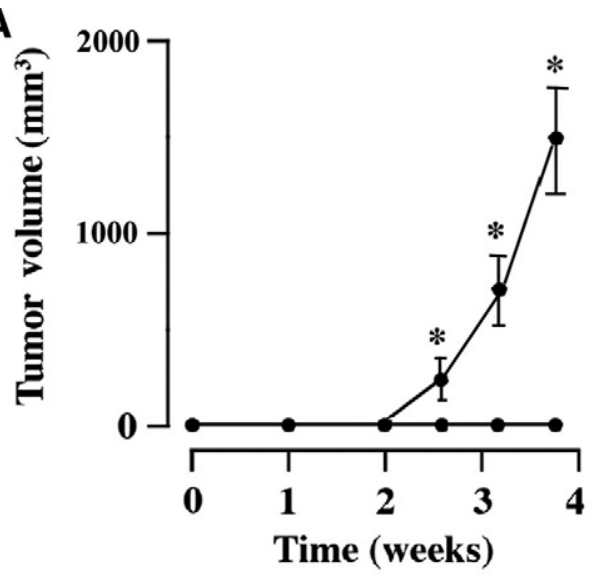

B

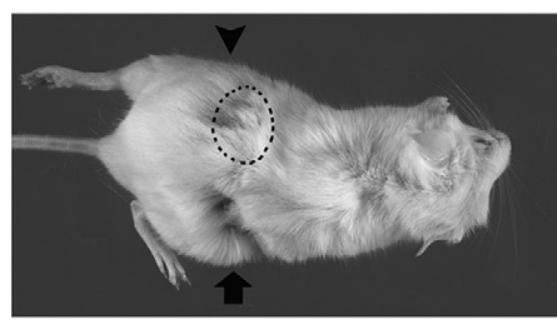

C

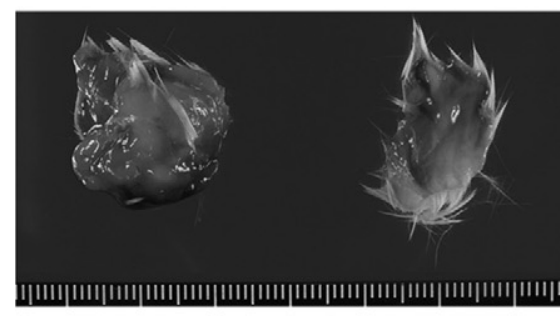

D

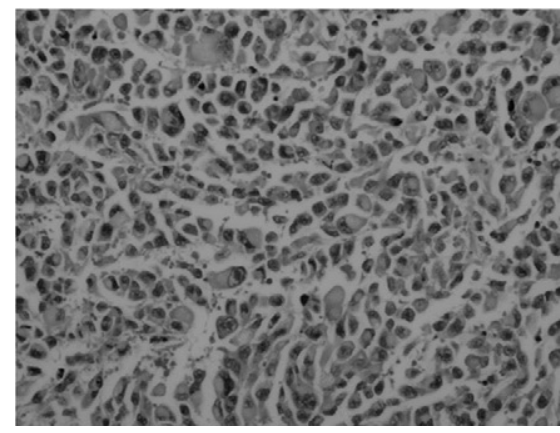

Figure 5. Xenotransplantation of $S$ and $M$ cells of L1236 into NOD/SCID mice. $\mathrm{S}$ and $\mathrm{M}$ cells were injected into the left (arrowhead) and right (arrow) flanks of NOD/SCID mice. A: The volume of tumors derived from S and M cells. The values are the mean \pm SE of three experiments. ${ }^{*} P<0.05$ by the Student's $t$-test. B: Tumor mass was found in the injected site of $S$ cells (arrowhead) but not of M cells (arrow). Tumor was found in dotted area. C: Resected tumor in the injected site of S cells (left). No tumor was found in the injected site of M (right). D: Resected tumor derived from S cells consisted of S and M cells $(\times 100)$.

ure 7A). Hematopoietic stem cells express FoxO3a at a high level, suggesting that CSCs of $\mathrm{HL}$ might show a high FoxO3a expression as well. As expected, the expression of FoxO3a was mostly confined to $\mathrm{S}$ cells, approximately $35 \%$ of $S$ cells, suggesting that $S$ cells contained a small population expressing FoxO3a at a high level and excluding ROS (Figure 7B). The expression level of catalase, whose expression was enhanced by FoxO3a, was also high in approximately $30 \%$ of S cells (Figure 7 C). In 


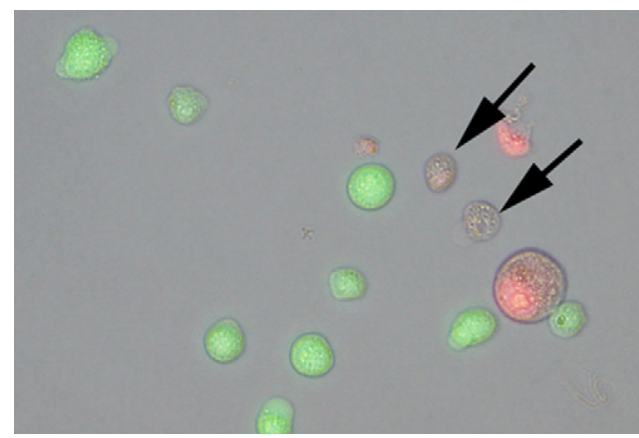

Figure 6. ROS concentration in S and M cells. ROS-high cells stained green and dead cells stained red. ROS-low viable cells are indicated by arrows

the clinical samples of $\mathrm{HL}$, mononuclear Hodgkin cells exclusively expressed FoxO3a, and multinucleated RS cells did not (Figure 7D).

\section{Effect of Insulin on the Formation of M Cells}

Insulin is known to cause the degradation of $\mathrm{FoxO} 3 a$ through PI3K pathway. To examine the role of FoxO3a for ROS degradation, insulin was added to the culture medium. The addition of insulin decreased the expression level of FoxO3a in S cells (Figure 8A). Approximately 10\% of $\mathrm{M}$ cells expressed $\mathrm{FoxO} 3 \mathrm{a}$, but the addition of insulin decreased its proportion to 3\% (Figure 8A). As compared to the culture without insulin, the proportion of $\mathrm{M}$ cells increased from $2 \%$ to $8 \%$ when insulin was added (Figure $8 \mathrm{~B})$. This increase of $\mathrm{M}$ cells was diminished by the addition of PI3K inhibitor LY294002 (Figure 8C). The addition of PI3K inhibitor alone without insulin did not affect the proportion of $\mathrm{M}$ cells (Figure $8 \mathrm{C}$ ). These findings showed that the addition of insulin to $\mathrm{S}$ cells enhanced the formation of $\mathrm{M}$ cells via PI3K pathway.

\section{Discussion}

$\mathrm{HL}$ is mostly a B-cell neoplasm which can be diagnosed by the presence of multinucleated cells with distinct inclusion-like nucleoli (so-called diagnostic RS cells) admixed with Hodgkin cells with single nucleus in which large nucleolus is discernible, small lymphoid cells, and various inflammatory cells. Precise study based on the analysis of immunoglobulin gene rearrangement and fusion pattern of terminal repeats in Epstein-Barr virus (EBV) for microdissected single cells from HL lesion revealed the monoclonal nature, thus neoplastic B-cell in nature, of the RS cells and Hodgkin cell. ${ }^{10,11}$ Here, the tumorigenic potential of these two types of cells was examined with HL cell line L1236 and L428. L1236 and L428 are composed of two types of cells, $S$ cells that resembles to Hodgkin cells and $\mathrm{M}$ cells that resembles to RS cells. $S$ and $M$ cells share a common immunophenotype; both express CD30 and CD15, but not CD20. ${ }^{13} \mathrm{EBV}$ DNA is not detectable in both $S$ and $M$ cells, because L1236 and L428 cells are derived from the HL without EBV infection. ${ }^{13,14}$

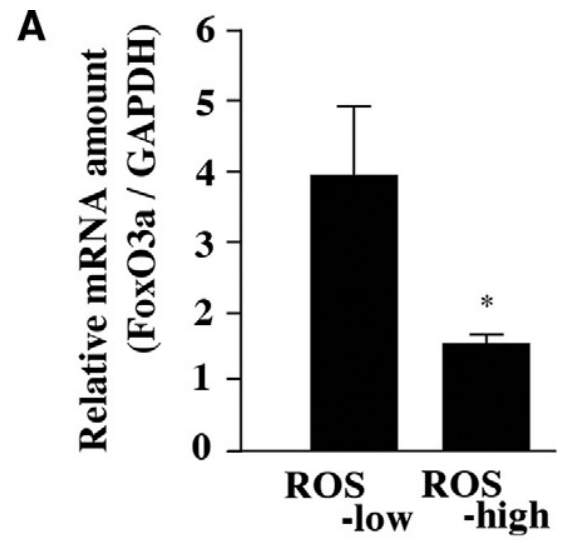

B
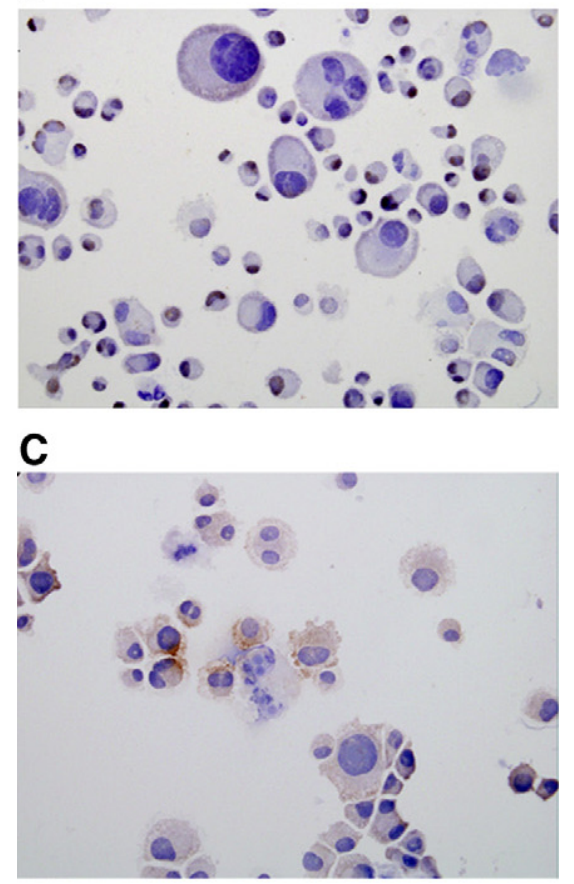

D

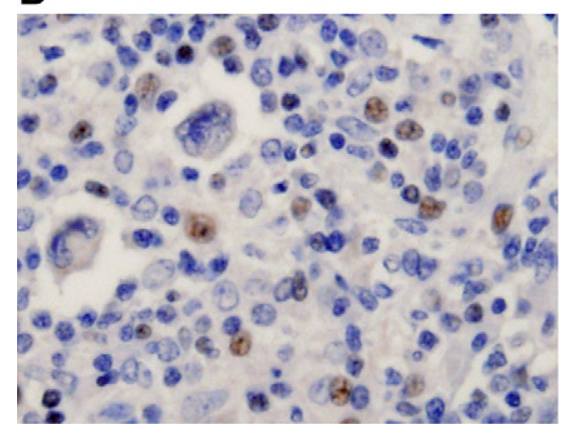

Figure 7. Expression of FoxO3a and catalase. A: Real-time quantitative RT-PCR for FoxO3a in ROS-low and -high L1236 cells. The values are the mean $\pm \mathrm{SE}$ of three experiments. ${ }^{*} P<0.05$ by the Student's $t$-test. Immunocytochemistry of FoxO3a $(\mathbf{B})$ and catalase $(\mathbf{C})$ in L1236 cells $(\times 400)$. D: Immunohistochemistry of FoxO3a in clinical samples of HL $(\times 400)$.

When the single $S$ cell was cultured, cell populations composed of $\mathrm{S}, \mathrm{M}$, and mixed of both were developed. In contrast, M cells hardly proliferated. Among 100 wells of a single cell culture of $\mathrm{M}$ cells, only one well yielded 


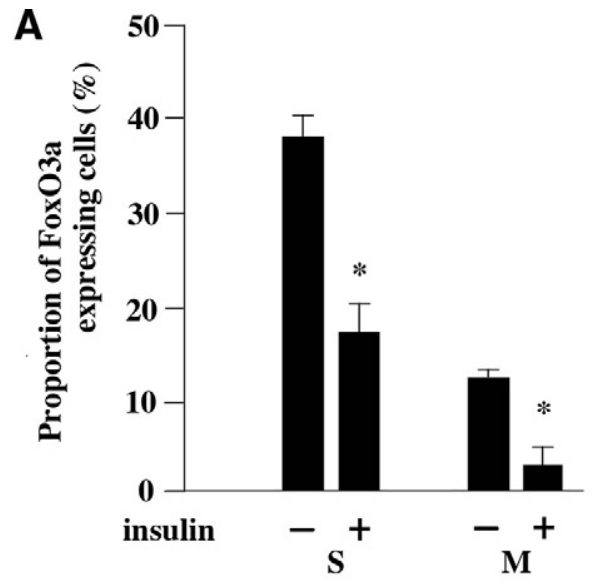

B
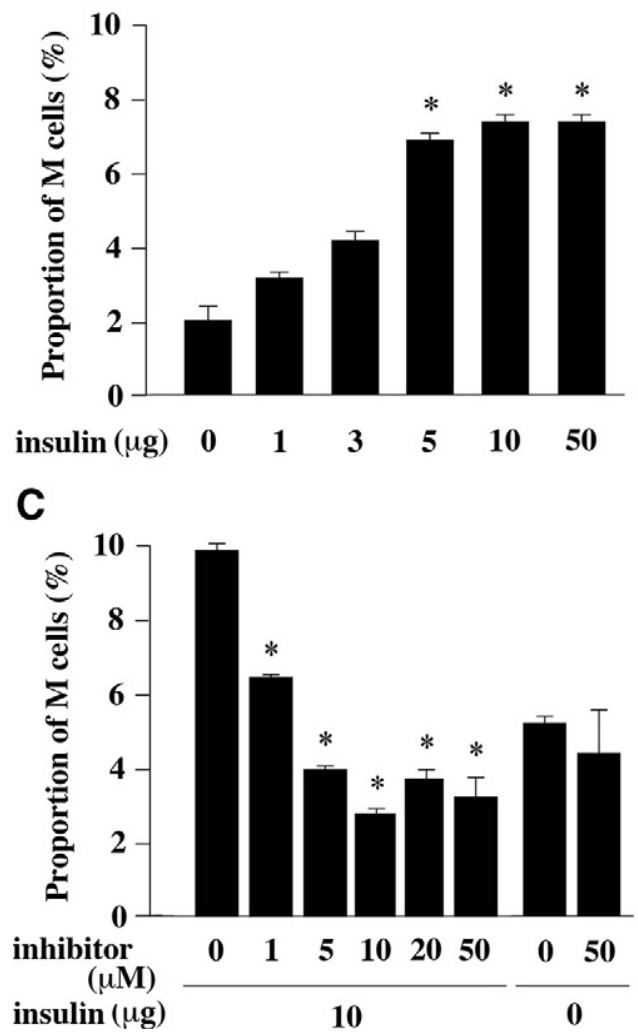

Figure 8. Effect of insulin on the formation of $M$ cells. A: Change of proportion of FoxO3a-expressing L1236 cells by the addition of insulin. B: Proportion of M cells among L1236 cultured with insulin. C: LY294002 inhibited the formation of $M$ cells. The values are the mean \pm SE of three experiments. ${ }^{*} P<0.05$ by the Student's $t$-test.

detectable cell population composing exclusively $\mathrm{M}$ cells. These findings indicated that a single cell culture of $S$ cells yielded both $S$ and $M$ cells. Whereas, $M$ cells showed a limited proliferative potential and yielded $\mathrm{M}$ cells but not $\mathrm{S}$ cells. The proportion of $\mathrm{Ki}-67$ or cyclin D2-positve, and BrdU-uptaking cells was generally higher in S cells than in M cells of both $\mathrm{L} 1236$ and $\mathrm{L} 428$ : approximately $30 \%$ and $10 \%$ in $\mathrm{Ki}-67,7 \%$ and $0 \%$ in cyclin D2, and 10\% and $0 \%$ in BrdU in L1236; $100 \%$ and $80 \%$ in $\mathrm{Ki}-67,9 \%$ and $2 \%$ in cyclin D2, and $40 \%$ and $10 \%$ in BrdU in L428, respectively. (The former value is $S$ and the latter is M.) These findings showed the limited prolif- erative potential of $\mathrm{M}$ cells. CSCs are known to yield both CSC and non-CSC, whereas non-CSCs yield only nonCSCs. ${ }^{8}$ Therefore cells with CSC character appeared to be present among $S$ cells. CSCs possess a strong tumorigenic ability when cultured in semisolid condition or transplanted into NOD/SCID mice. In methycellulose culture and inoculation into NOD/SCID mice, the number of colonies and the size of tumors were larger in $\mathrm{S}$ cells than in $\mathrm{M}$ cells. These findings supported the above-mentioned notion that CSCs were present among S cells.

Wolf et al ${ }^{13}$ reported the xenotransplantation of $2 \times 10^{7}$ of L1236 cells into Scid mice: tumor was formed at 6 weeks after transplantation, reached the size of 0.5 to 1 $\mathrm{cm}$ in diameter, then regressed completely. Whereas the tumor was not spontaneously regressed even after reaching the diameter of approximately $2 \mathrm{~cm}$ at up to 4 weeks in present study. This might be partly explained that the injected cells were not the original L1236 but the selected $\mathrm{S}$ cell population. In the current study, $2 \times 10^{3}$ $S$ cells were enough to form tumors at 2 week after transplantation, suggesting that the $\mathrm{S}$ cells selected from mixed population possessed more tumorigenic potential than nonselected L1236 cells. Higher proportion of Ki-67, cyclin D2-positive, and BrdU-uptaking cells among $S$ cells than $\mathrm{M}$ cells found in the present study explained more tumorigenic potential of $S$ cells than $\mathrm{M}$ cells.

Next, we further characterized the $S$ cells. Recently, CSCs have been reported to possess the ability to keep the concentration of ROS at a low level. ${ }^{9}$ Then, $\mathrm{H}_{2} \mathrm{O}_{2}$ was added to L1236, and the concentration of ROS in each cell type was measured with $\mathrm{CM}-\mathrm{H}_{2}$ DCFDA. M cells and most of $\mathrm{S}$ cells showed high ROS concentration in the presence of $\mathrm{H}_{2} \mathrm{O}_{2}$, but the concentration was at a low level in a portion of $\mathrm{S}$ cells. $\mathrm{FoxO} 3 \mathrm{a}$ is a transcription factor regulating the expression of ROS-degrading enzymes, such as catalase. ${ }^{16-19}$ A portion of $S$ cells exclusively expressed FoxO3a and catalase, whereas $\mathrm{M}$ cells did not. In the clinical samples of $\mathrm{HL}$, FoxO3a was expressed mainly in the mononuclear Hodgkin cells but not in the multinucleated RS cells. These findings suggested that approximately $10 \%$ of $\mathrm{S}$ cells keeping ROS concentration at a low level and showing high FoxO3a and catalase expression might be a candidate for CSCs of HL.

Recently, Jones reported the circulating clonotypic B cell population with small sizes and high expression of aldehyde dehydrogenase and CD27 in HL patients. ${ }^{20}$ This population efficiently formed colonies in vitro. These findings were similar to those found in the S cells population reported in our study. Further studies will clarify the relation between these two populations.

Wolf et $\mathrm{al}^{13}$ described that L1236 may not be a representative $\mathrm{HL}$ cell line due to numerous chromosomal aberrations and atypical karyotype for $\mathrm{HL}$. Then, another $\mathrm{HL}$ cell line L428, which shows fewer chromosomal aberrations than L1236, was examined in the present study, and the similar results were obtained. ${ }^{21,22}$ Although the limited proliferative potential of $\mathrm{M}$ cells might be due to the culture system, we considered that $\mathrm{S}$ cells possessed tumorigenic potential as compared to $\mathrm{M}$ cells based on the in vivo xenotransplantation experiment, the distinct 
higher expression level of Ki-67 and cyclin D2, and BrdU uptake in $\mathrm{S}$ than in $\mathrm{M}$ cells.

It is reported that activation of PI3K pathway suppresses the FoxO3a expression. ${ }^{23}$ It is known that many reagents, including insulin, activate $\mathrm{PI} 3 \mathrm{~K} .{ }^{23,24}$ If FoxO3a plays a role for maintenance of CSCs in $\mathrm{HL}$, the addition of insulin might result in decrease of number of tumorigenic $S$ cells and increase of nontumorigenic $M$ cells. As expected, the addition of insulin increased the proportion of M cells, and this was inhibited by LY294002, an inhibitor for PI3K pathway. Yilmaz et al and Zhang et al reported that the hematopoitetic stem cells are diminished when phosphatase and tensin homolog (PTEN), an antagonist against PI3K, is knocked-out. ${ }^{25,26}$ It is suggested that the activation of PI3K pathway appeared to decrease the stem cell activity not only in hematopoietic system but also in $\mathrm{HL}$.

Taken together, among morphologically distinctive $\mathrm{HL}$ neoplastic cells, a portion of single-nucleated cells was tumorigenic and possess CSC-like characters.

\section{Acknowledgments}

We thank Megumi Sugano, Etsuko Maeno, and Takako Sawamura for their technical assistance.

\section{References}

1. Bonnet D, Dick JE: Human acute myeloid leukemia is organized as a hierarchy that originates from a primitive hematopoietic cell. Nat Med 1997, 3:730-737

2. Lessard J, Sauvageau G: Bmi-1 determined the proliferative capacity of normal and leukaemic stem cells. Nature 2003, 423:255-260

3. Al-Hajj M, Wicha MS, Benito-Hernandez A, Morrison SJ, Clarke MF: Prospective identification of tumorigenic breast cancer cells. Proc Natl Acad Sci USA 2003, 100:3983-3988

4. Singh SK, Hawkins C, Clarke ID, Squire JA, Bayani J, Hide T, Henkelman RM, Cusimano MD, Dirks PB: Identification of human brain tumour initiating cells. Nature 2004, 432:396-401

5. Reya T, Morrison SJ, Clarke MF, Weissman IL: Stem cells, cancer, and cancer stem cells. Nature 2001, 414:105-111

6. O'Brien CA, Pollett A, Gallinger S, Dick JE: A human colon cancer cell capable of initiating tumor growth in immunodeficient mice. Nature 2007, 445:106-110

7. Ricci-Vitiani L, Lombardi DG, Pilozzi E, Biffoni M, Todaro M, Peschle C, De Maria R: Identification and expansion of human colon-cancerinitiating cells. Nature 2007, 445:111-115

8. Kondo T, Setoguchi T, Taga T: Persistence of a small subppulation of cancer stem-like cells in the C6 glioma cell line. Proc Natl Acad Sci USA 2004, 101:781-786

9. Diehn M, Cho RW, Lobo NA, Kalisky T, Dorie MJ, Kulp AN, Qian D, Lam JS, Ailles LE, Wong M, Joshua B, Kapian MJ, Wapnir I, Dirbas FM, Somlo G, Garberoglio C, Paz B, Shen J, Lau SK, Quake SR, Brown JM, Weissman IL, Clarke MF: Association of reactive oxygen species levels and radioresistance in cancer stem cells. Nature 2009, 458:780-783

10. Kanzler H, Kuppers R, Hansmann ML, Rajewsky K: Hodgkin and Reed-Sternberg cells in Hodgkin's disease represent the outgrowth of a dominant tumor clone derived from (crippled) germinal center B cells. J Exp Med 1996, 184:1495-1505

11. Marofioti T, Hummel M, Foss HD, Laumen H, Korbjuhn P, Anagnostopoulos I, Lammert H, Demel G, Theil J, Wirth T, Stein H: Hodgkin and reed-sternberg cells represent an expansion of single clone originating from a germinal center B-cell with functional immunoglobulin gene rearrangements but defective immunoglobulin transcription. Blood 2000, 95:1443-1450

12. Hsu SM, Zhao X, Chakraborty S, Liu YF, Whang-Peng J, Lok MS, Fukuhara S: Reed-Sternberg cells in Hodgkin's cell lines HDLM. $\mathrm{L}-428$, and $\mathrm{KM}-\mathrm{H} 2$ are not actively replicating: lack of bromodeoxyuridine uptake by multinuclear cells in culture Blood 1988, 71:13821389

13. Wolf J, Kapp U, Bohlen H, Kornacker M, Schoch C, Stahl B, Mucke S, von Kalle C, Fonatsch C, Schaefer HE, Hansmann ML, Diehl V: Peripheral blood mononuclear cells of a patient with advanced Hodgkin's lymphoma give rise to permanently growing HodgkinReed Sternberg cells. Blood 1996, 87:3418-3428

14. Schaadt M, Diehl V, Stein H, Fonatsch C, Kirchner HH: Two neoplastic cell lines with unique features derived from Hodgkin's disease. In J Cancer 1980, 26:723-731

15. Meyer-Siegler KL, Iczknowski KA, Leng L, Bucala R, Vera PL: Inhibition of macrophage migration inhibitory factor or its receptor (CD74) attenuates growth and invasion of DU-145 prostate cancer cells. J Immunol 2006, 177:8730-8739

16. Tothova Z, Kollipara R, Huntly BJ, Lee BH, Castrillon DH, Cullen DE, McDowell EP, Lazo-Kallanian S, Williams IR, Sears C, Armstrong SA, Passegue E, DePinho RA, Gilliland DG: FoxOs are critical mediators of hematopoietic stem cell resistance to physiologic oxidative stress. Cell 2007, 128:325-339

17. Miyamoto K, Araki KY, Naka K, Arai F, Takubo K, Yamazaki S, Matsuoka S, Miyamoto T, Ito K, Ohmura M, Chen C, Hosokawa K, Nakauchi H, Nakayama K, Nakayama KI, Harada M, Motoyama N, Suda T, Hirano A: FoxO3a is essential for maintenance of hematopoietic stem cell pool. Cell Stem Cell 2007, 1:101-112

18. Ito K, Hirano A, Arai F, Matsuoka S, Takubo K, Hamaguchi I, Nomiyama K, Hosokawa K, Sakurada K, Nakagata N, Ikeda Y, Mak TW, Suda T: Regulation of oxidative stress by ATM is required for self-renewal of hematopoietic stem cells. Nature 2004, 431:997-1002

19. Ito K, Hirano A, Arai F, Takubo K, Matsuoka S, Miyamoto K, Ohmura M, Naka K, Hosokawa K, Ikeda Y, Suda T: Reactive oxygen species act through p38 MAPK to limit the lifespan of hematopoietic stem cells. Nat Med 2006, 12:446-451

20. Jones RJ, Gocke CD, Kasamon YL, Miller CB, Perkins B, Barber JP Vala MS, Gerber JM, Gellert LL, Siedner M, Lemas MV, Brennan S, Ambinder RF, Matsui W: Circulating clonotypic B cells in classic Hodgkin lymphoma. Blood 2009, 113:5920-5926

21. Diehl V, Kirchner HH, Burrichter H, Stein H, Fonatsch C, Gerdes J, Schaadt M, Heit W, Uchanska-Ziegler B, Ziegler B, Ziegler A, Heintz F, Sueno K: Characteristics of Hodgkin's disease-derived cell lines. Cancer Treat Rep 1982, 66:615-632

22. Fonatsch C, Diehl V, Schaadt M, Burrichter H, Kirchner HH: Cytogenetic investigations in Hodgkin's disease: i. Involvement of specific chromosomes in marker formation. Cancer Genet Cytogenet 1986, 20:39-52

23. Van Der Heide LP, Hoekman MF, Smidt MP: The ins and outs of FoxO shuttling: mechanisms of FoxO translocation and transcriptional regulation. Biochem J 2004, 380:297-309

24. Liu L, Xie Y, Lou L: :PI3K is required for insulin-stimulated but not EGF-stimulated ERK1/2 activation. Eur J Cell Biol 2006, 85:367-374

25. Yilmaz OH, Valdez R, Theisen BK, Guo W, Ferguson DO, Wu H, Morrison SJ: Pten dependence distinguishes haematopoietic stem cells from leukaemia-initiating cells. Nature 2006, 441:475-482

26. Zhang J, Grindley JC, Yin T, Jayasinghe S, He XC, Ross JT, Haug JS, Rupp D, Porter-Westpfahl KS, Wiedemann LM, Wu H, Li L: PTEN maintains haematopoietic stem cells and acts in lineage choice and leukaemia prevention. Nature 2006, 441:518-522 